\title{
Suicidality and Personality Pathology in Adolescence: A Systematic Review
}

\author{
Marta Moselli ${ }^{1} \cdot$ Maria Pia Casini ${ }^{2} \cdot$ Camilla Frattini $^{1} \cdot$ Riccardo Williams $^{1}$ (i)
}

Accepted: 15 August 2021 / Published online: 15 September 2021

(c) The Author(s) 2021

\begin{abstract}
This work presents a review of research papers examining the role of emerging personality pathology in suicidal ideation and behaviours in adolescence. Initially, 226 studies were selected in line with PRISMA guidelines, and 33 articles were finally included in this review. The data show percentages of any personality disorder diagnosis ranging from 19.5 to $22.8 \%$ in suicide attempters, while in autopsy studies, the rate of personality disorder diagnosis varied between 29.6 and $42.1 \%$. The overwhelming majority of the studies focus on the role of borderline personality disorder (BPD) in suicidal behaviours, also highlighting its predictive role at a longitudinal level. Furthermore, the literature review shows that personality traits supposed to underlie BPD, such as affective instability, impulsivity and identity diffusion, have specific predictive links with suicidal conduct. Other personality pathology dimensions, such as aggressiveness, sadism and perfectionism that are associated with other personality disorders, namely, antisocial and narcissistic personality disorders, have also shown a significant mediating role for suicidal risk. Overall, these results seem to parallel the role of personality pathology in predicting suicide in adulthood and point to the relevance of assessing the presence of emerging patterns of personality disorders for the clinical management of suicidal risk in adolescence.
\end{abstract}

Keywords Adolescence $\cdot$ Suicidal conducts $\cdot$ Suicidal risk $\cdot$ Personality pathology $\cdot$ Review

\section{Introduction}

Suicide is considered a public health problem worldwide, and the World Health Organization has declared its reduction as a primary objective at a global level [1]. Suicide is the second-leading cause of death after road accidents in subjects aged between 12 and 34 years [2,3], and the maximum peak incidence of suicidal behaviours and suicidal ideation is indeed observed during adolescence [4]. The literature on suicidality both in adulthood and adolescence has shown the interaction of an array of potential risk factors in determining the shift from suicidal ideation to actual suicidal conduct. Consequently, diverse risk factors

Moselli Marta and Casini Maria Pia are joint first authors.

Riccardo Williams

riccardo.williams@uniroma1.it

1 Department of Clinical and Dynamic Psychology, Sapienza University of Rome, Rome, Italy

2 Child Neuropsychiatry Unit, Department of Neuroscience, I.R.C.C.S. Children Hospital Bambino Gesù, Rome, Italy have been investigated, although the specific factors that may reliably differentiate high- and low-risk patients have not yet been fully defined. Among the risk factors for suicide, psychiatric disorders have been considered prominent. The psychiatric disorder most frequently associated with suicidal behaviours-both in adulthood and in adolescenceis major depression, whether in its unipolar form or as an episode in a bipolar disorder [5, 6]. It has also been shown that personality disorders (PDs) represent a severe risk factor for suicidality in adulthood [7, 8]. In fact, a meta-analysis of 27 psychological autopsy studies reported that $16 \%$ of adult suicide victims had been diagnosed with a PD [9]. Moreover, studies have shown that the younger the onset of suicidal behaviours, the higher the likelihood of a cooccurrence of a diagnosis of cluster B PDs [10-13]. In fact, the diagnosis of PDs in adolescence has been a controversial matter: recent innovations proposed by both the alternative model for PD in the Diagnostic and Statistical Manual of Mental Disorders, 5th edition (DSM-5) ("Materials and Methods" section) and International Classification of Diseases, 11th revision (ICD-11) reflect increasing attention towards the assessment of personality pathology during 
this developmental age [13]. In fact, the DSM-5 allows the diagnosis of PD in adolescence if a greater than 1-year pattern of immature personality development with disturbances in different specific domains (depending on the type of PD) is observed [14]. In fact, diagnoses of PDs in adolescence regularly show both concurrent and predictive stability with respect to measures of functional impairment and psychopathology in many domains of adjustment throughout the life span $[13,15]$. Furthermore, over time, adolescents with significant functional impairments often shift from one diagnostic category to another [16]. Overall, in both the developmental and adulthood literatures, this instability and discontinuity of PD diagnoses - 'heterotypic continuity'-have led to a possible reformulation of PDs as clinical variants of underlying basic psychobiological dimensions that present robust developmental stability and significant genetic loading [17-21]. Following this indication, the DSM-5 has introduced a dimensional-categorical PD hybrid model with the aims of reducing comorbidity and improving the validity and stability of diagnoses [22]. The presence of PDs in adolescence, especially those of clusters $\mathrm{B}$ and $\mathrm{C}$, has been associated with a high risk of suicidal ideation and suicide attempts, including at a prospective level in early adulthood [13]. Adolescents suffering from a PD are at greater risk of developing many of the problems associated with suicidal behaviour, and although the implications for the risks of attempted and completed suicide may differ, personality pathology is implicated in both conditions [23]. Although studies investigating the presence of PDs in adolescent populations with suicidal behaviours have shown a significant prevalence of PDs in these samples [24-26], to date, there is no systematic review examining suicidality and personality pathology in adolescence. In this paper, we propose to provide such a review by employing both the categorical approach based on diagnoses of PDs in adolescence and the dimensional approach investigating those personality traits that, according to empirical literature, are more consistently related to personality pathology during the lifespan.

Given the impact of suicidal conduct in adolescence and the relevance of personality pathology for suicidality in adulthood, this review has the following aims:

(1) To assess the prevalence and the association of any DSM and ICD personality disorder diagnosis, traits (number of criteria met for any disorder) or dimensions with suicidal ideations and conduct in adolescence in both clinical and community populations.

(2) To assess the prevalence and the association of DSMand ICD-specific personality disorder diagnosis, traits (number of criteria met for any disorder) or dimensions with suicidal ideations and conduct in adolescence in both clinical and community populations.
(3) To assess the association of personality pathological dimensions/traits associated with DSM- or ICD-specific personality disorders with suicidal ideations and conduct in adolescence in both clinical and community populations.

\section{Materials and Methods}

\section{Literature Search}

A systematic search of the PubMed/MEDLINE research literature databases was carried out to identify relevant, peerreviewed articles on personality disorders/traits/dimensions in adolescents with suicidal behaviours. The search syntax was based on combinations of the following terms: personality AND (disorder OR pathology OR traits) AND (suicide OR suicide attempt) AND (adolesc* OR child*) AND [(“1980/01/01”[PDat]: “2020/01/01”[PDat])]. The search was undertaken from 1 March 2017 to 30 January 2020. We also examined reports as well as the abstracts from recent psychiatric research conferences. This systematic review was performed in accordance with Preferred Reporting Items for Systematic Reviews and Meta-Analyses (PRISMA) guidelines [27].

\section{Study Selection}

We included studies investigating the prevalence of PDs or trait diagnoses and personality dimensions commonly associated with PDs, e.g., those observed in the suicidal population, both in clinical and community samples. We also included studies examining the prevalence of suicidality in both clinical and community samples screened for assessments of personality disorders, traits and dimensions in association with adolescents' suicidal ideation or behaviour. All studies included in this review considered clinical or community populations with subjects aged between 13 and 18 years old. Regarding the definition of suicidality, we referred to the Columbia Classification Algorithm of Suicide Assessment (Posner, 2007) and included studies dealing with suicidal ideation, suicidal intention, suicidal plans and suicidal behaviours. Studies dealing with self-harming behaviours that did not clearly facilitate the identification of subjects with the idea or intention to die were excluded. Regarding PD diagnoses, we included studies published since 1980, the year that the DSM-III was published, as it introduced the categories of PDs as we know them today. No study focusing on an alternative model of DSM-5 PDs with respect to suicidality was found. The following contributions were excluded from our review: reviews, metaanalyses, editorials, letters and comments, case reports and studies not based on standardized criteria. Two experienced 
investigators (C.F. and M.M.) reviewed the titles and abstracts of the retrieved articles and applied the study's inclusion and exclusion criteria. These investigators then independently reviewed the full-text articles to confirm the studies' eligibility for inclusion.

\section{Data Extraction}

For each included study, two authors (C.F. and M.M.) collected basic information (authors, reference citation, year, country) and study characteristics, including research design, diagnostic methods, diagnoses and rates of PDs, other diagnoses and comorbidities, participant counts, proportions by sex, age range and mean, rates of suicide attempts, definition of suicide attempt, methods of evaluating attempts and follow-up.

\section{Results}

To achieve a complete and clear-cut picture, the results regarding each objective will be divided into cross-sectional and longitudinal sections. The literature search generated 2576 potential records, plus one from the grey literature of initially identified reports, resulting in 230 records to be screened. Of these, 157 were excluded for the following reasons, as shown in Fig. 1: they included adults or did not separate adults from juveniles $(n=121)$; they were reviews, meta-analyses or case report articles $(n=17)$; they did not include personality or suicidality assessments $(n=13)$; or they did not use the English language $(n=6)$. Among the 73 selected research studies, 40 full-text articles were excluded because they did not separate suicidal ideation or behaviour from non-suicidal self-injury (NSSI) or self-harm and instead either examined only self-harming behaviour, were letters to editors or clinical trial or drug therapy efficacy studies, were focused on non-pathological personality traits, or assessed personality pathology only in adulthood (Fig. 1). The remaining 33 articles had different focuses, analysing the presence of PDs overall, specific personality categories and pathological personality traits in samples with suicidal ideation and/or suicide attempts and completed suicides.

\section{Overall Personality Disorders}

\section{Cross-sectional Studies}

Four studies investigated the relationship between suicidality and the presence of PDs overall. With respect to actual suicidal behaviour, the presence of any PD was found in $19.5-22.8 \%$ of adolescents who attempted suicide [28, 29] and in $29.6-42.1 \%$ of adolescent suicide victims [30, 31], with higher percentages obtained when cumulating PDs and traits as diagnosed using the ICD-10 criteria (Table 1). Tairi et al. found a subgroup at greater risk in an adolescent attempter population characterized by a PD [32].

\section{Longitudinal Studies}

In Ayodeji et al. s' study, the diagnosis of any PD was significantly associated with the severity of suicidal ideation [33].

\section{Specific Personality Disorder Categories}

\section{Cross-sectional Studies}

Only two autopsy studies investigated the prevalence of specific PD diagnoses in suicidal victims according to the ICD-10 criteria, revealing different distributions between the two studies. In Houson et al. s' study [30], considering both the categorical diagnosis and the number of criteria, the disorder most frequently diagnosed was the ICD-10 diagnosis of emotionally unstable, which corresponds to the DSM borderline personality disorder (BPD) diagnosis, as shown in Table 1. In Portzky et al. s' study [31], the most frequent diagnosis was dissocial personality disorder (Table 1). In both studies, other common PD diagnoses were paranoid personality disorder, dependent personality disorder, anankastic personality disorder and anxious personality disorder (Table 1). The overwhelming majority of studies focused on BPD based on DSM criteria, as shown in Table 1. All cross-sectional studies reported a high prevalence of BPD diagnoses in the suicidal population, except for one study in which the percentage of BPD diagnoses amounted to $6 \%$ of the clinical sample [37]. The frequency of BPD varied between 56.3 and $90.9 \%$ when considering suicidality in terms of both ideation and behaviours [34-36]. Regarding suicide attempts, the percentages ranged from 6 to $27 \%$ in clinical inpatient and outpatient samples of fewer than 100 subjects [37-39] and from 48.6 to $62 \%$ in samples with more than 100 subjects $[40,41]$. Finally, studying suicidal risk in an inpatient sample, Shelby and Yen [42] found $40 \%$ of patients with BPD (Table 1). Only two studies investigated suicidal behaviours in BPD samples [43, 44], showing a high incidence of suicide attempts (51.5-76\%), as displayed in Table 1. Kawashima and colleagues compared suicide attempters in a mixed adult and adolescent sample, reporting that adolescent attempters were more frequently diagnosed with BPD and were often dealing with the experience of losing a parent or were having problems at school [39]. According to Yen and colleagues, BPD patients had a higher likelihood of being hospitalized for attempting suicide and a higher rate of previous suicide attempts [45]. The relevance of BPD for suicidality in adolescence has also been stressed in studies showing the mediating role of BPD on suicidal ideation and conduct, adding to the impact of mood 


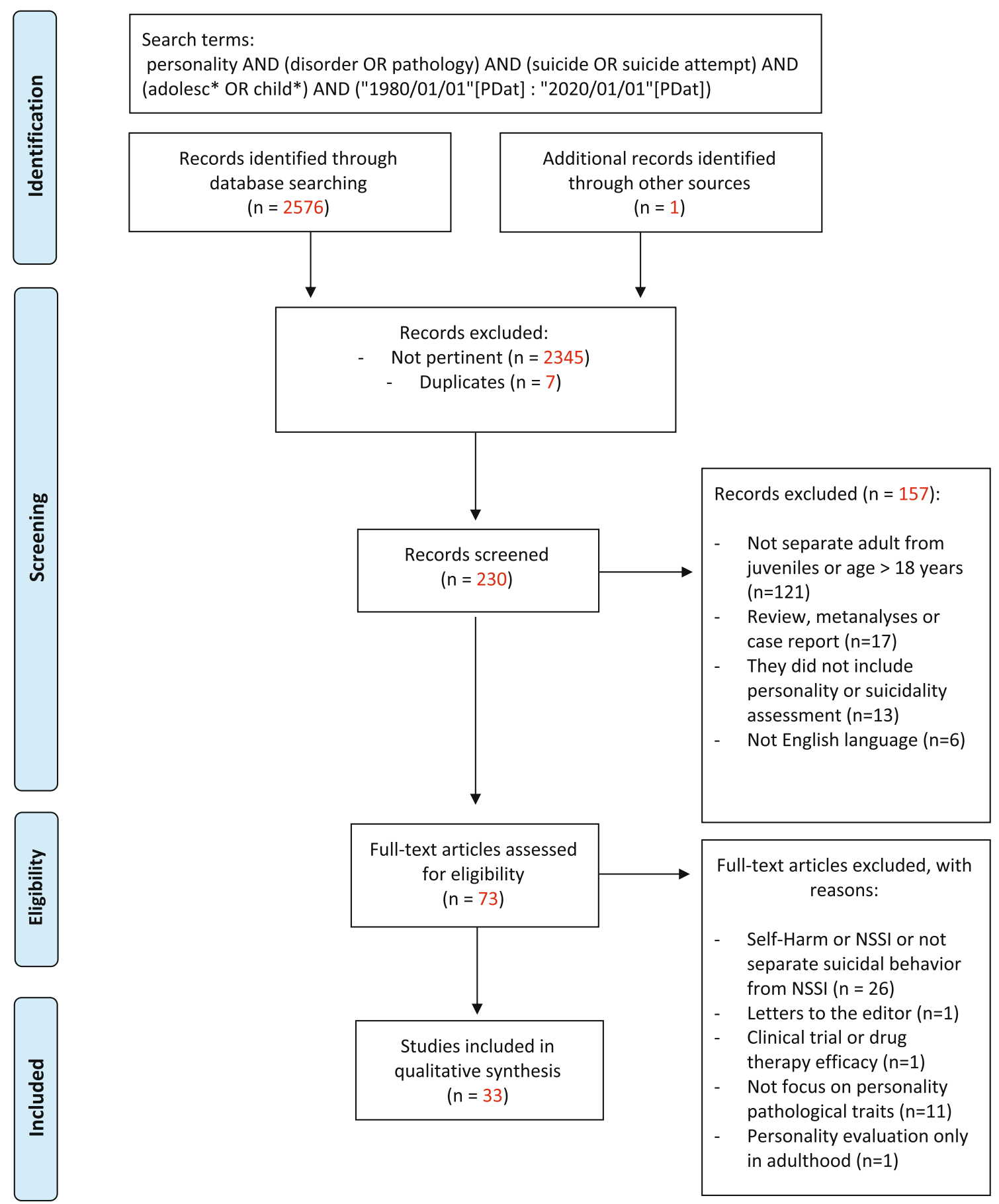

Fig. 1 Preferred Reporting Items for Systematic Reviews and MetaAnalyses (PRISMA). Reproduced with permission. [27] (C) 2009 Moher et al. From: Moher D, Liberati A, Tetzlaff J, Altman DG, The

disorders. Rodgers et al. found that BPD traits represented a significant mediation factor of the effects of depression on suicidal ideation [46]. Moreover, Sharp et al. explored suicide-related behaviours in a psychiatric sample of adolescents at a cross-sectional level, finding that the presence of BPD compared to major depression (MDD) resulted in an
PRISMA Group (2009). Preferred Reporting Items for Systematic Reviews and Meta-Analyses: The PRISMA Statement. PLoS Med 6(7): e1000097. https://doi.org/10.1371/journal.pmed1000097

increased risk of suicidal ideation [47]. Accordingly, some studies have indicated that specific BPD features can incrementally influence suicidality above the effects of symptoms of depression, substance abuse and other examples of psychopathology [35, 41, 45]. Yalch et al. considered the association between suicide risk and specific BPD features 


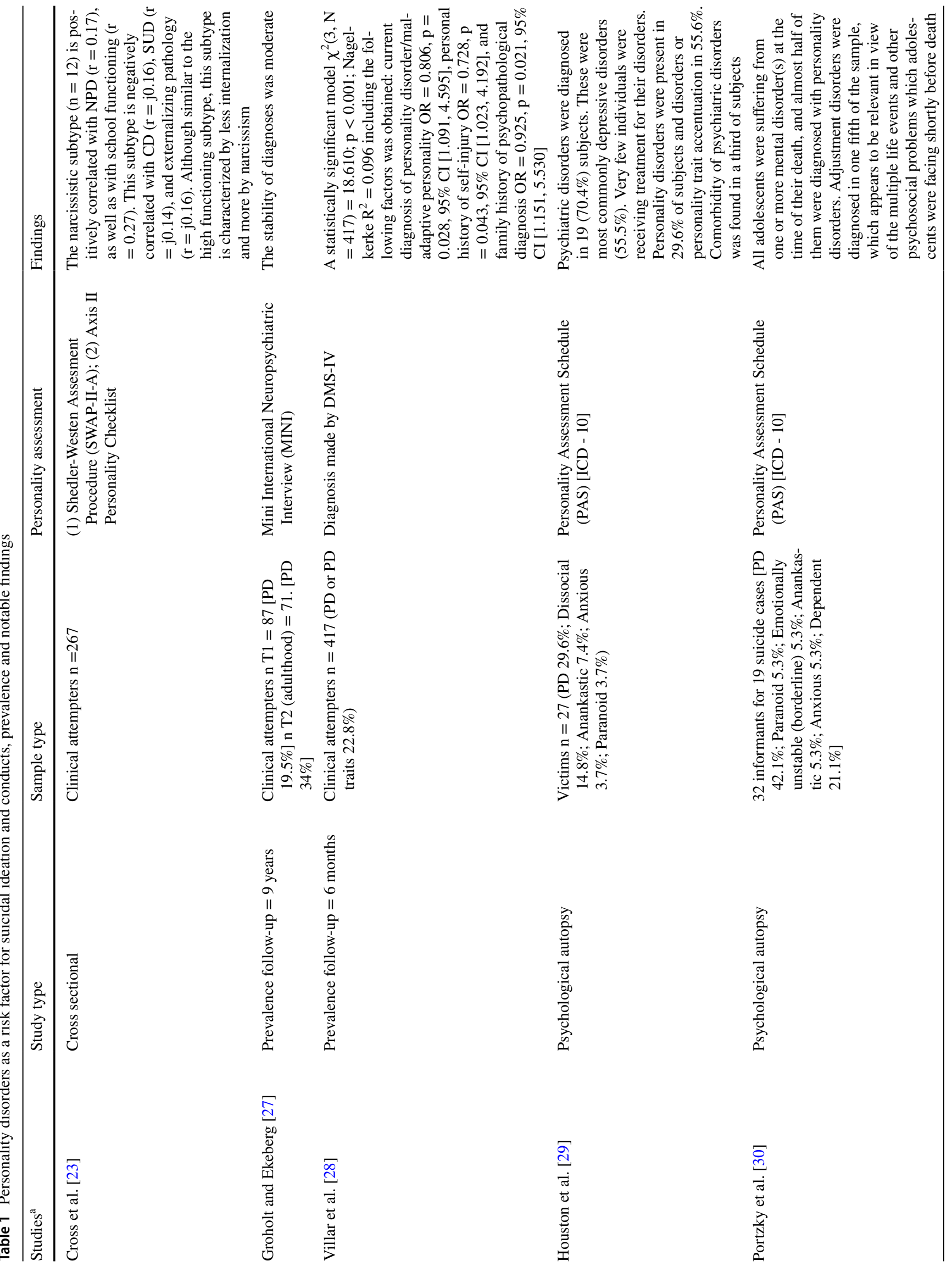




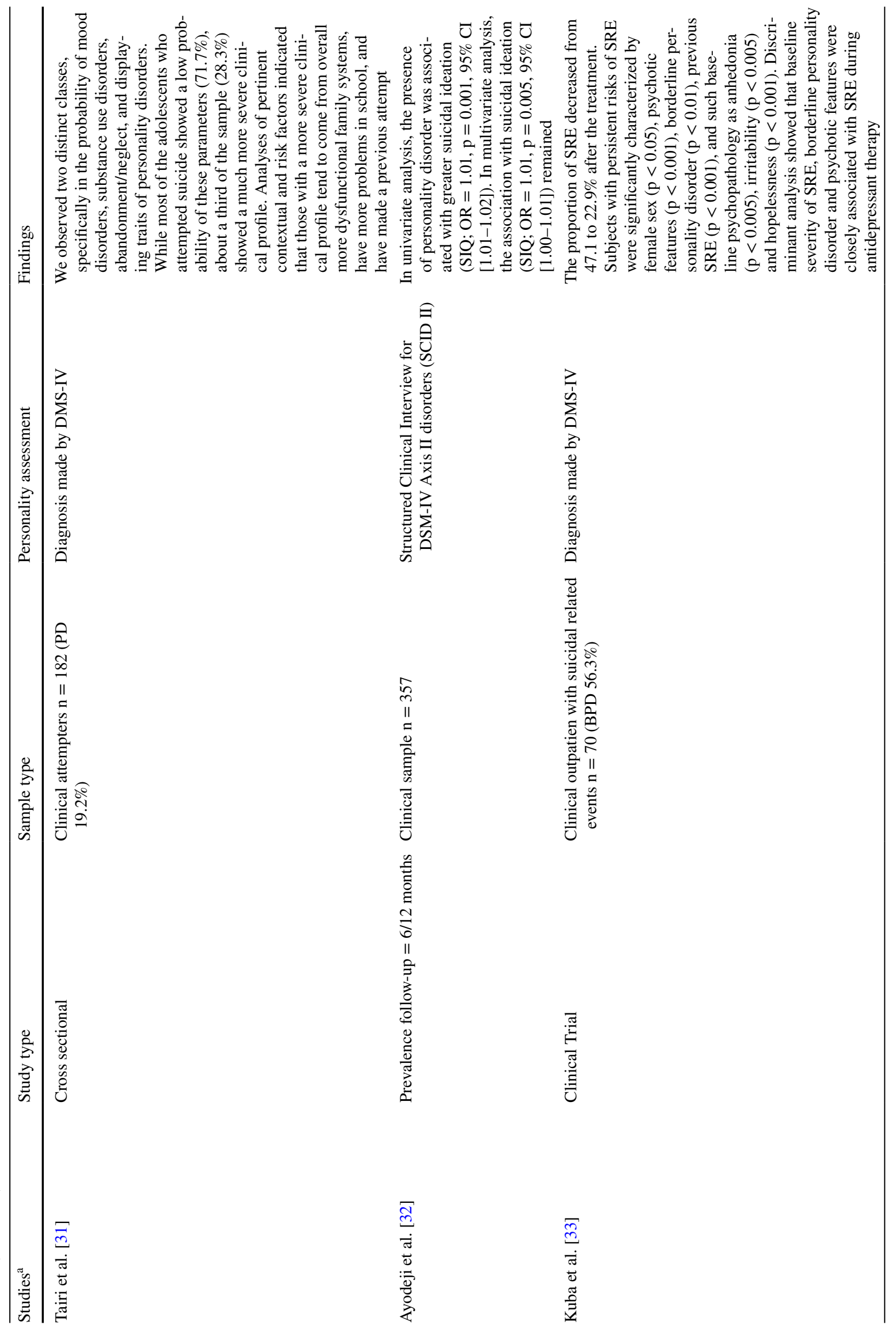




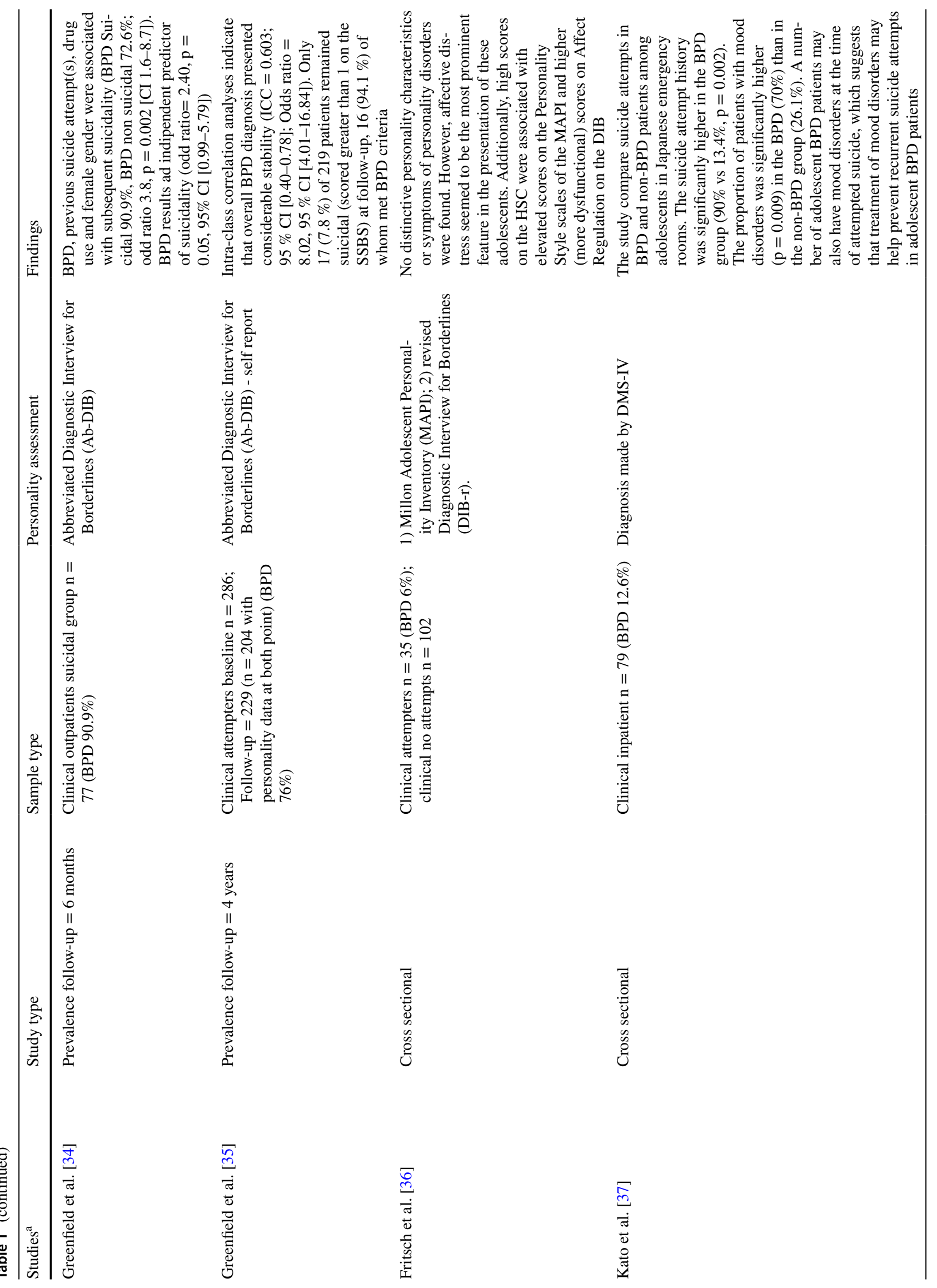


Child Psychiatry \& Human Development (2023) 54:290-311

297

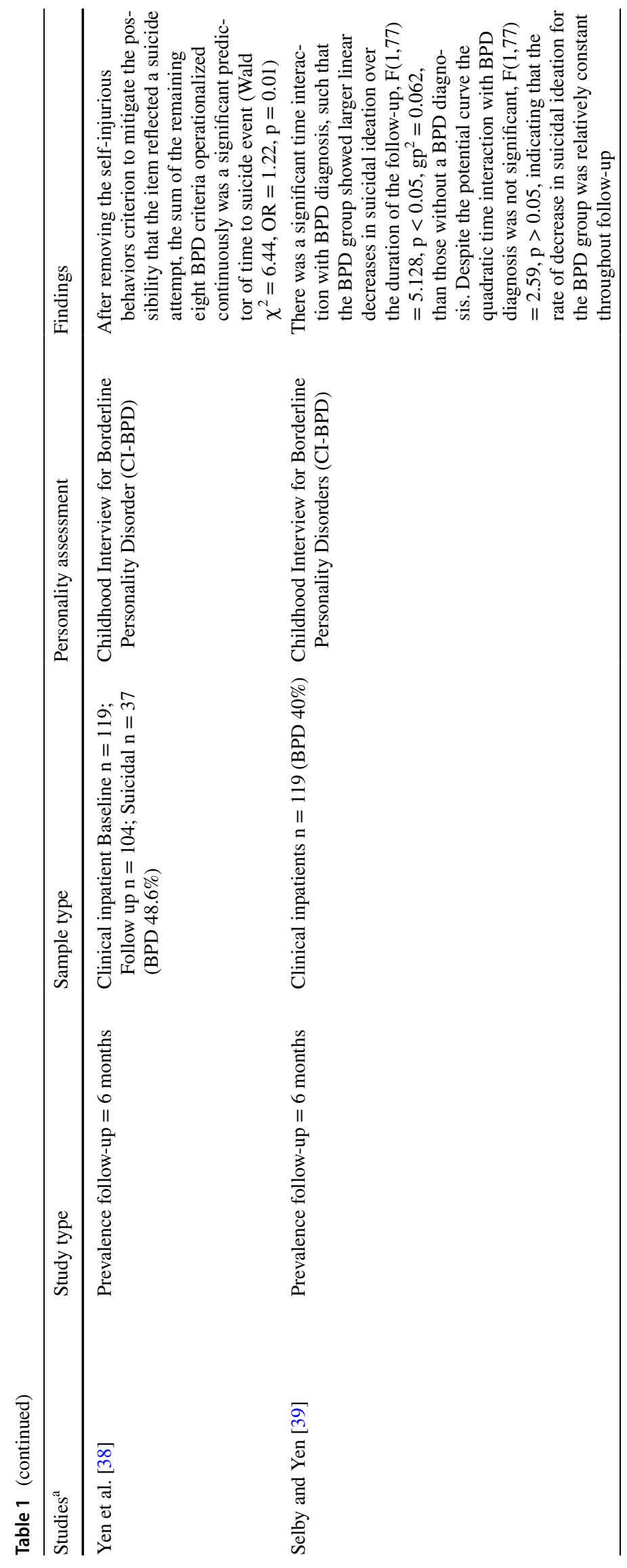

包 Springer 


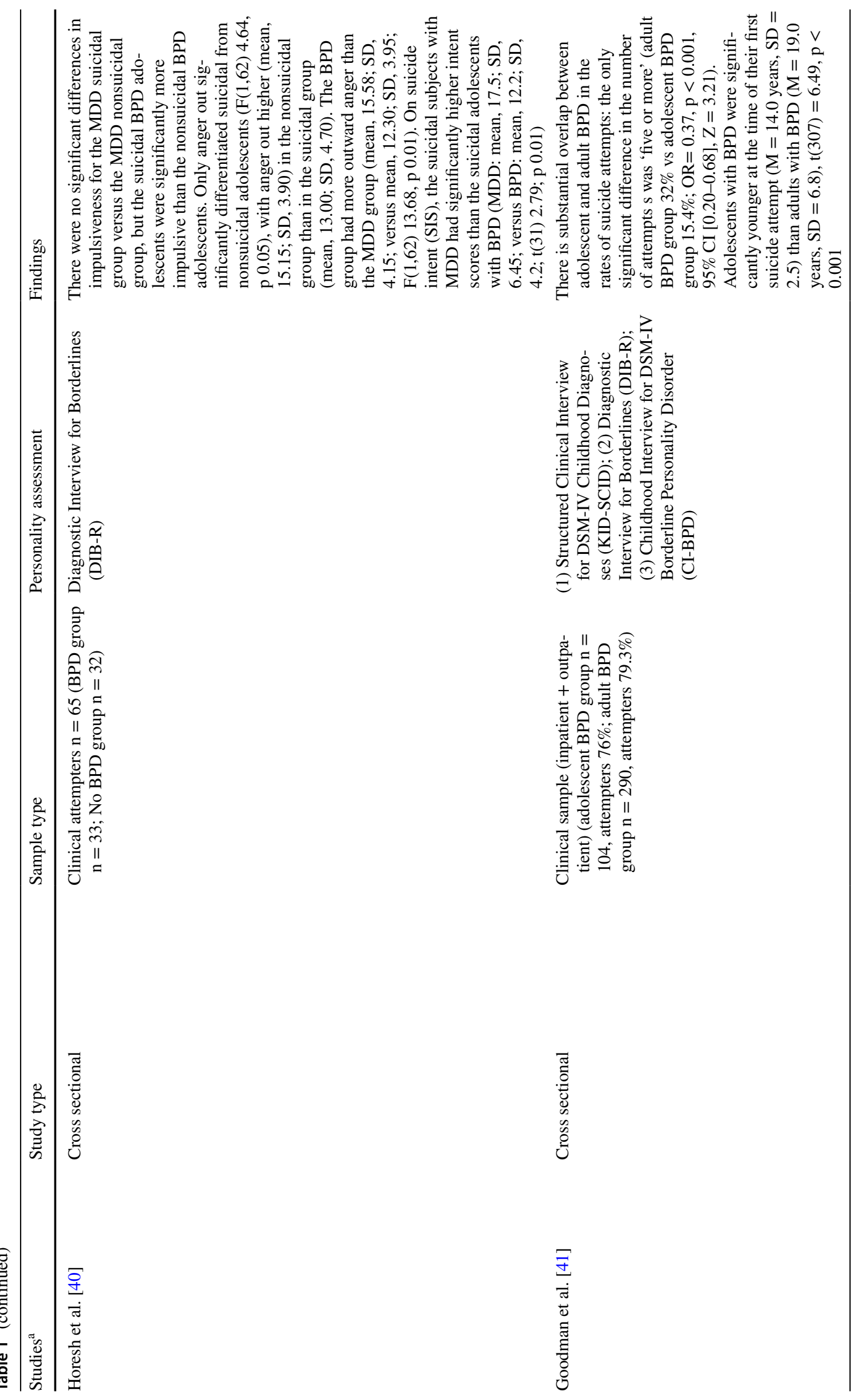




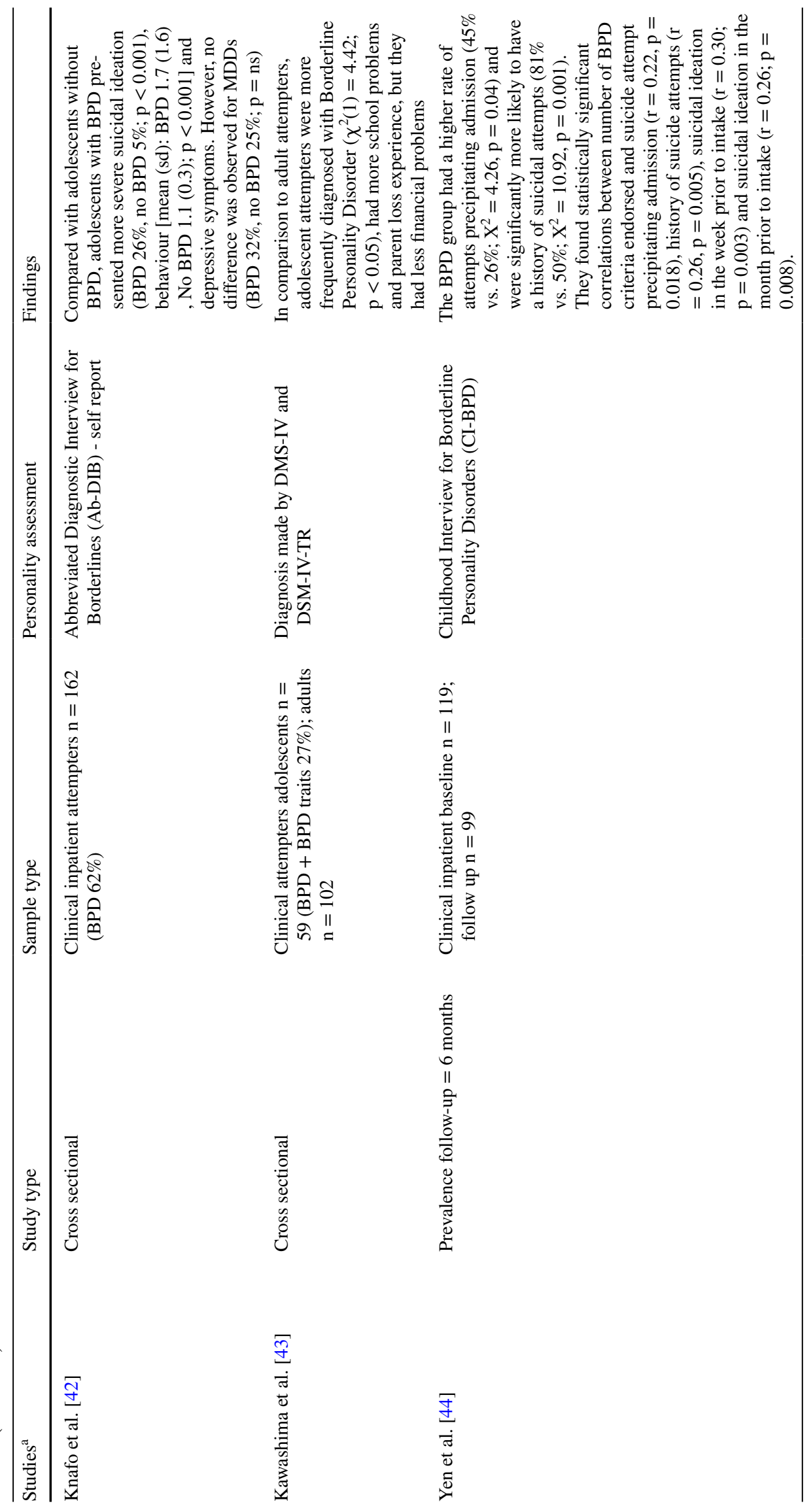




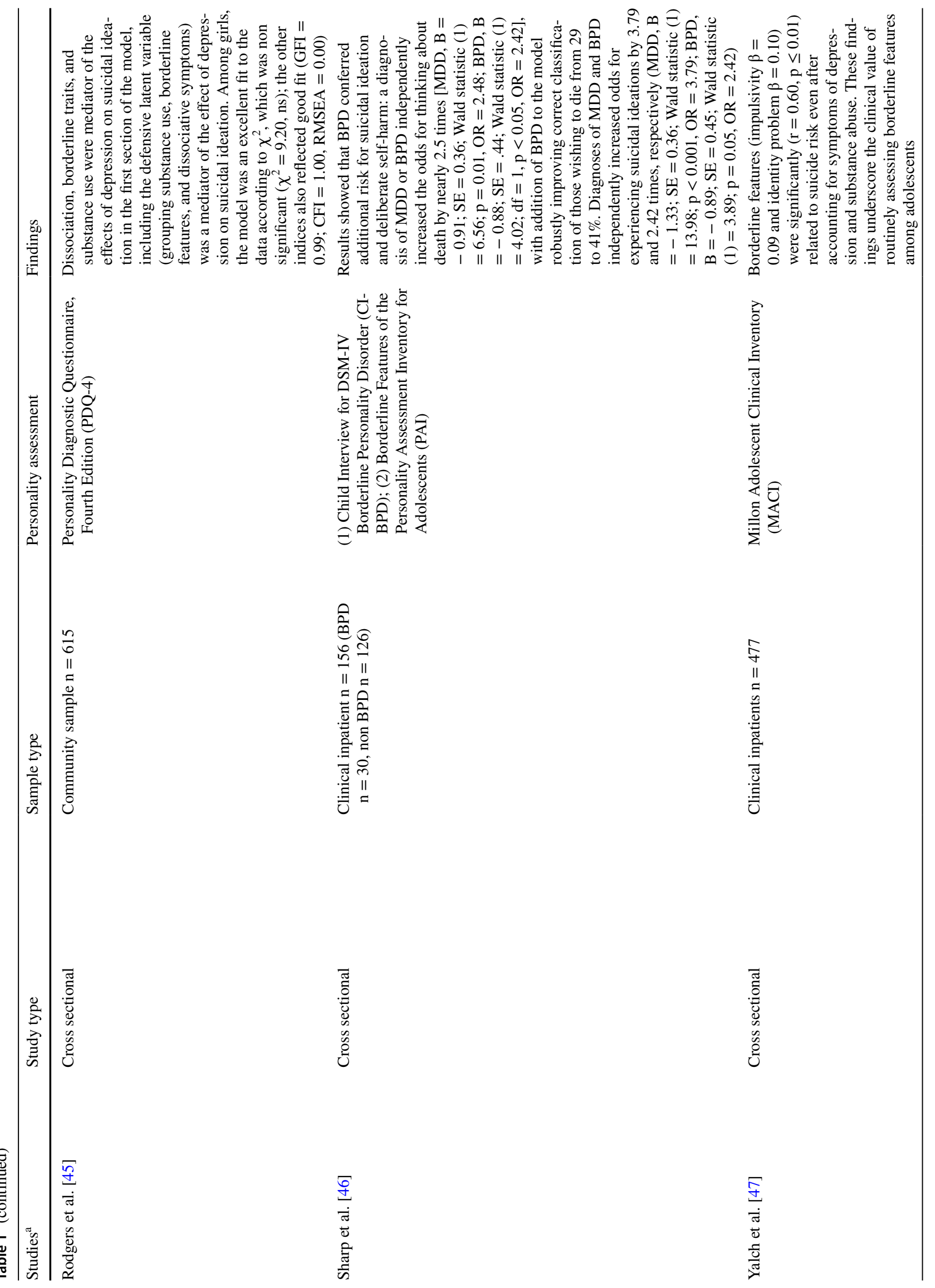




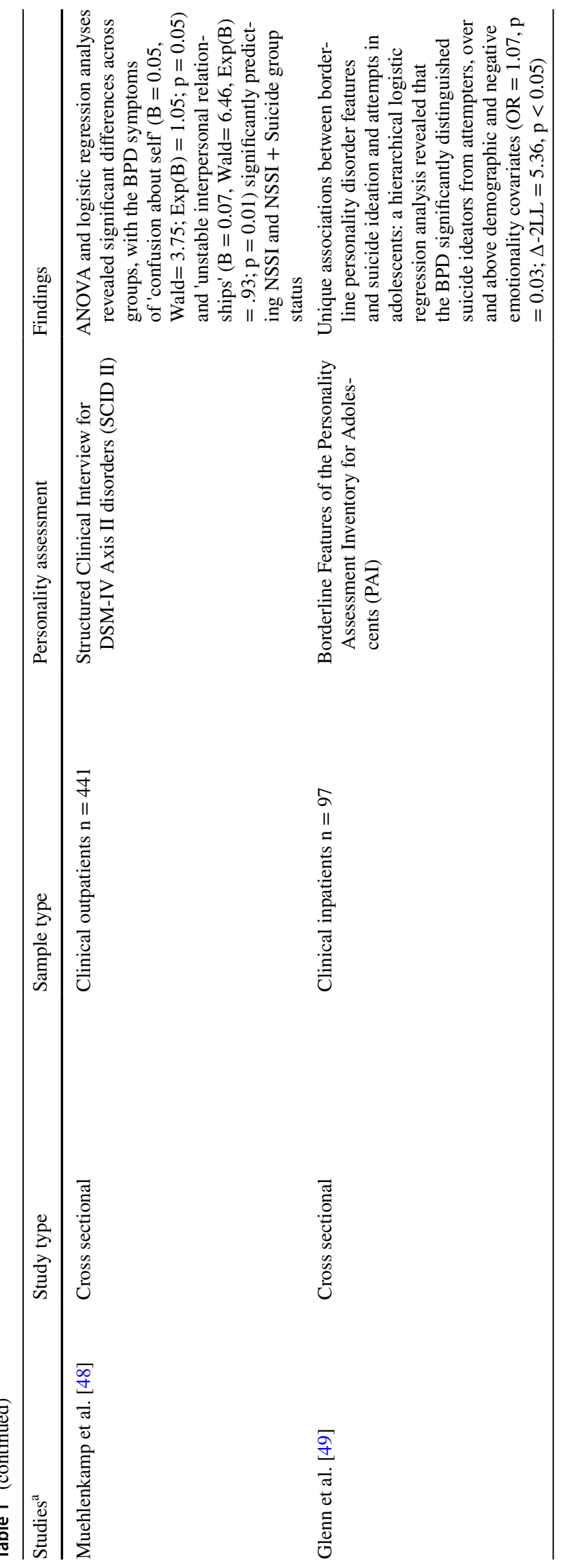




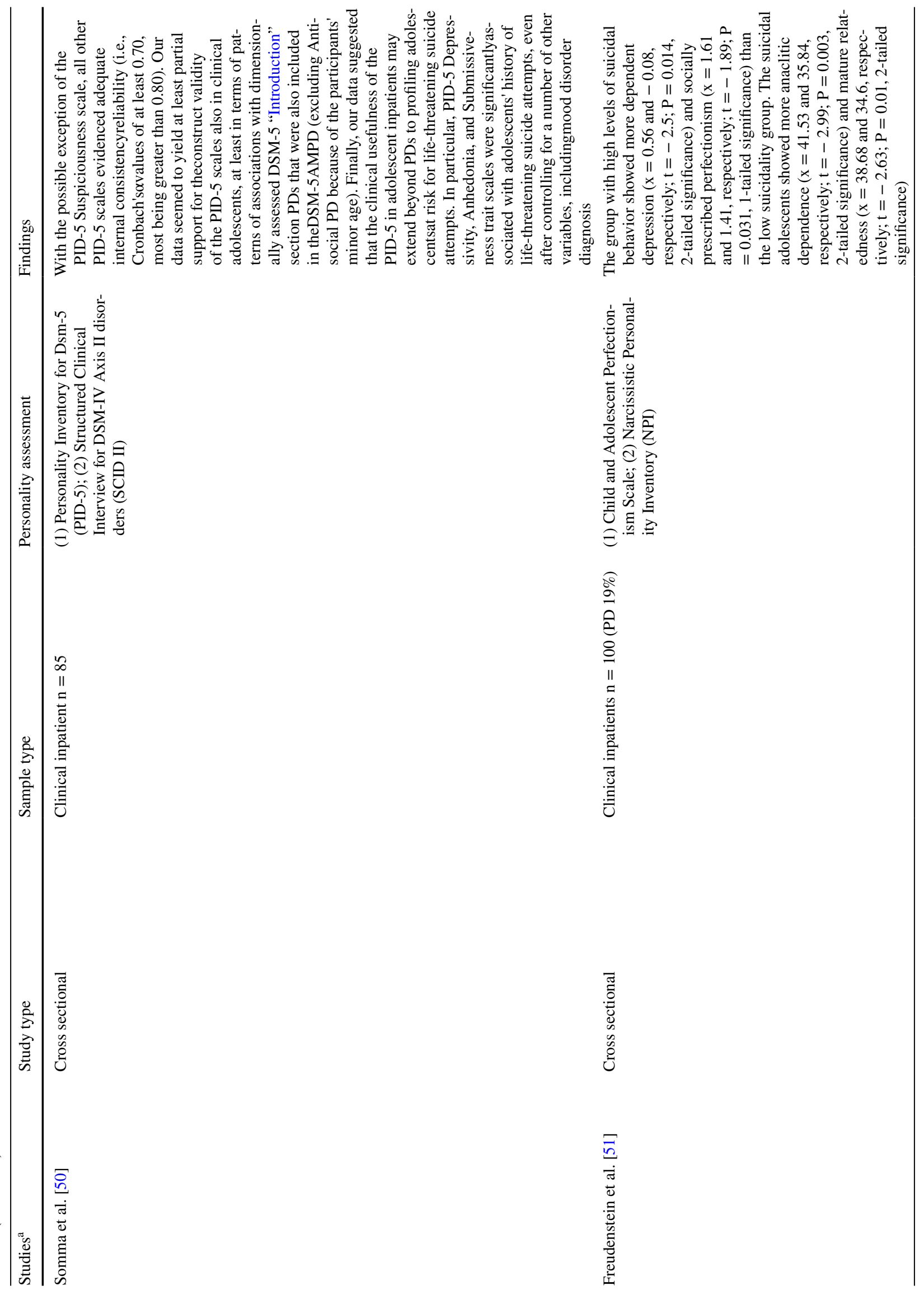




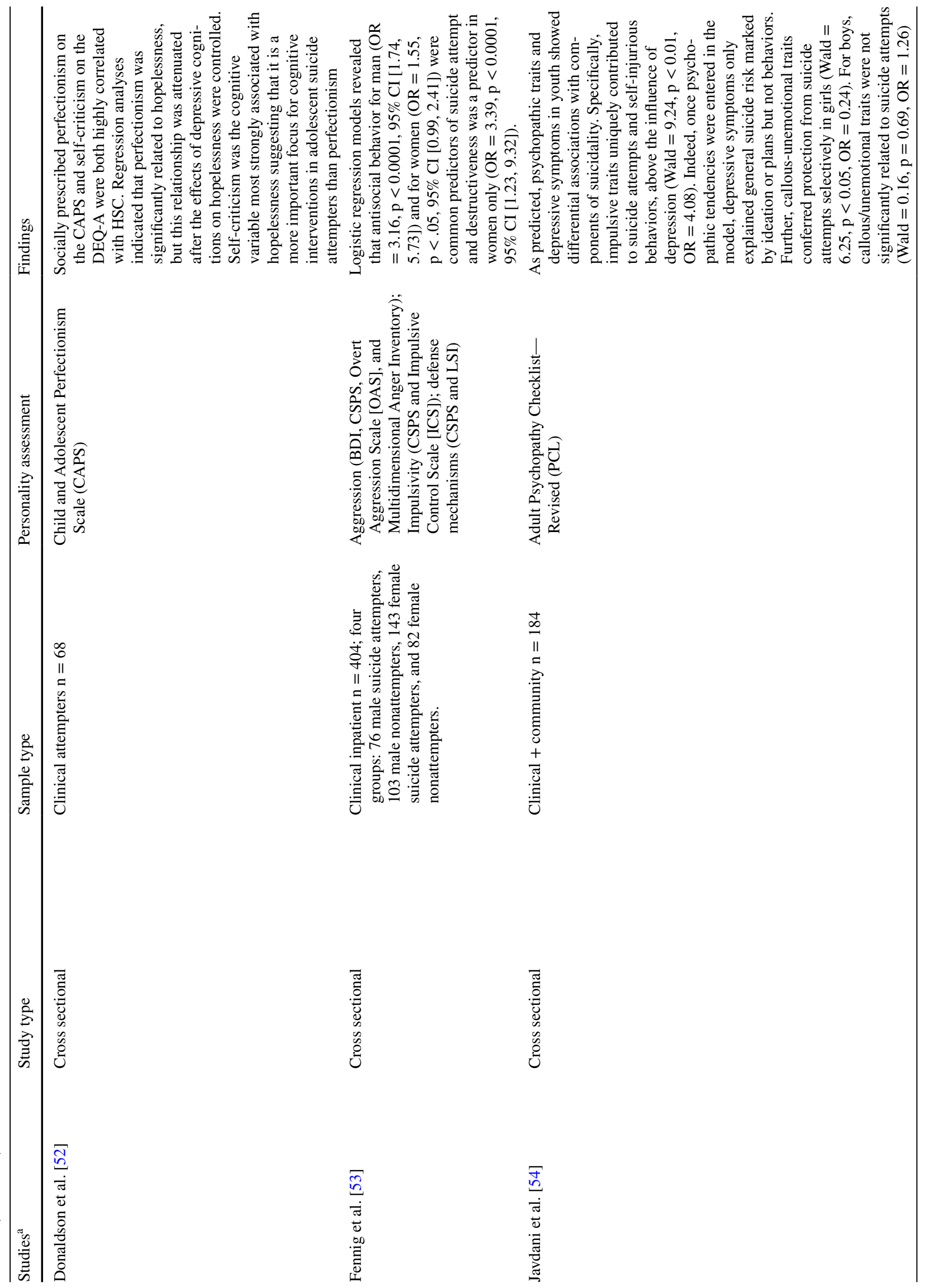




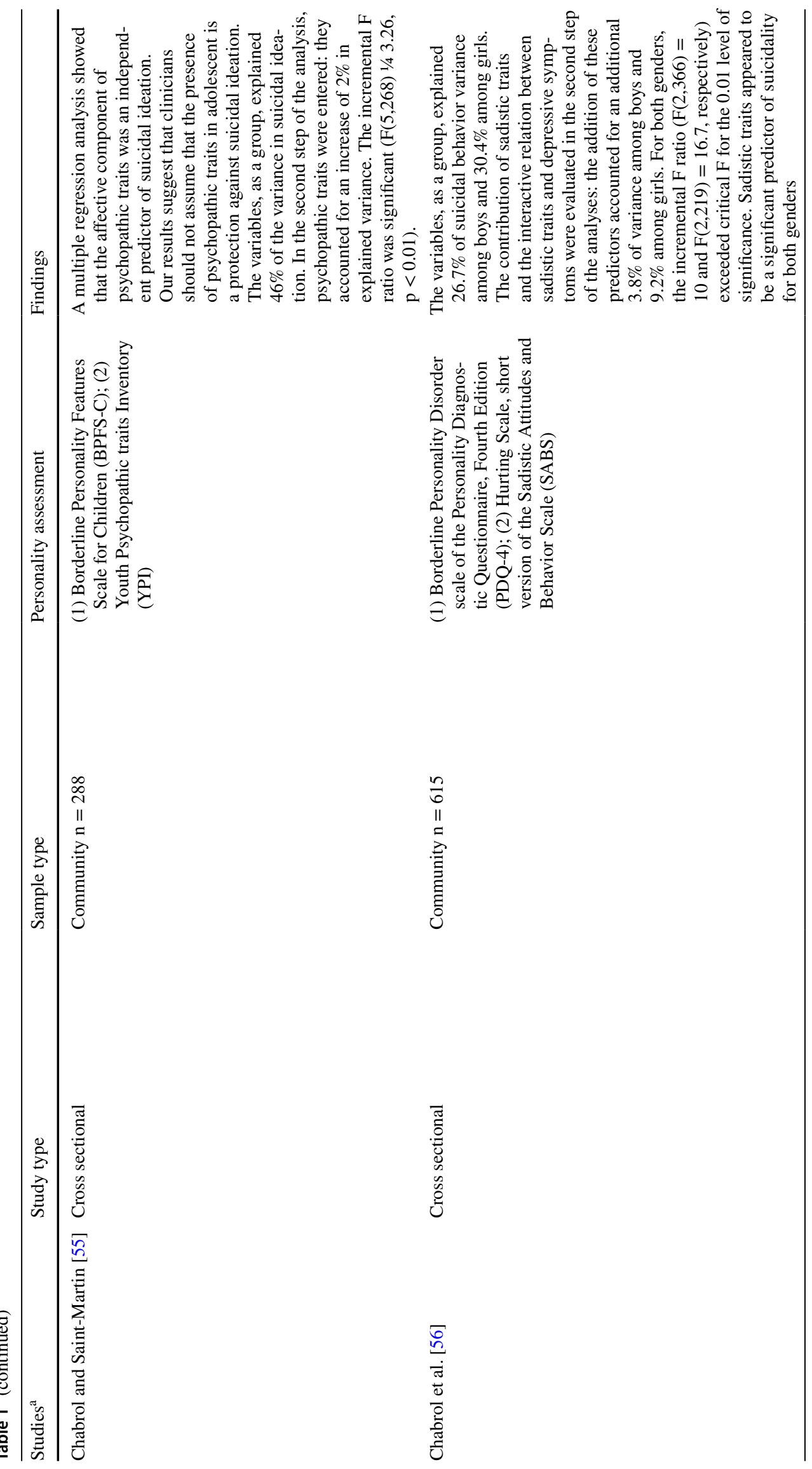




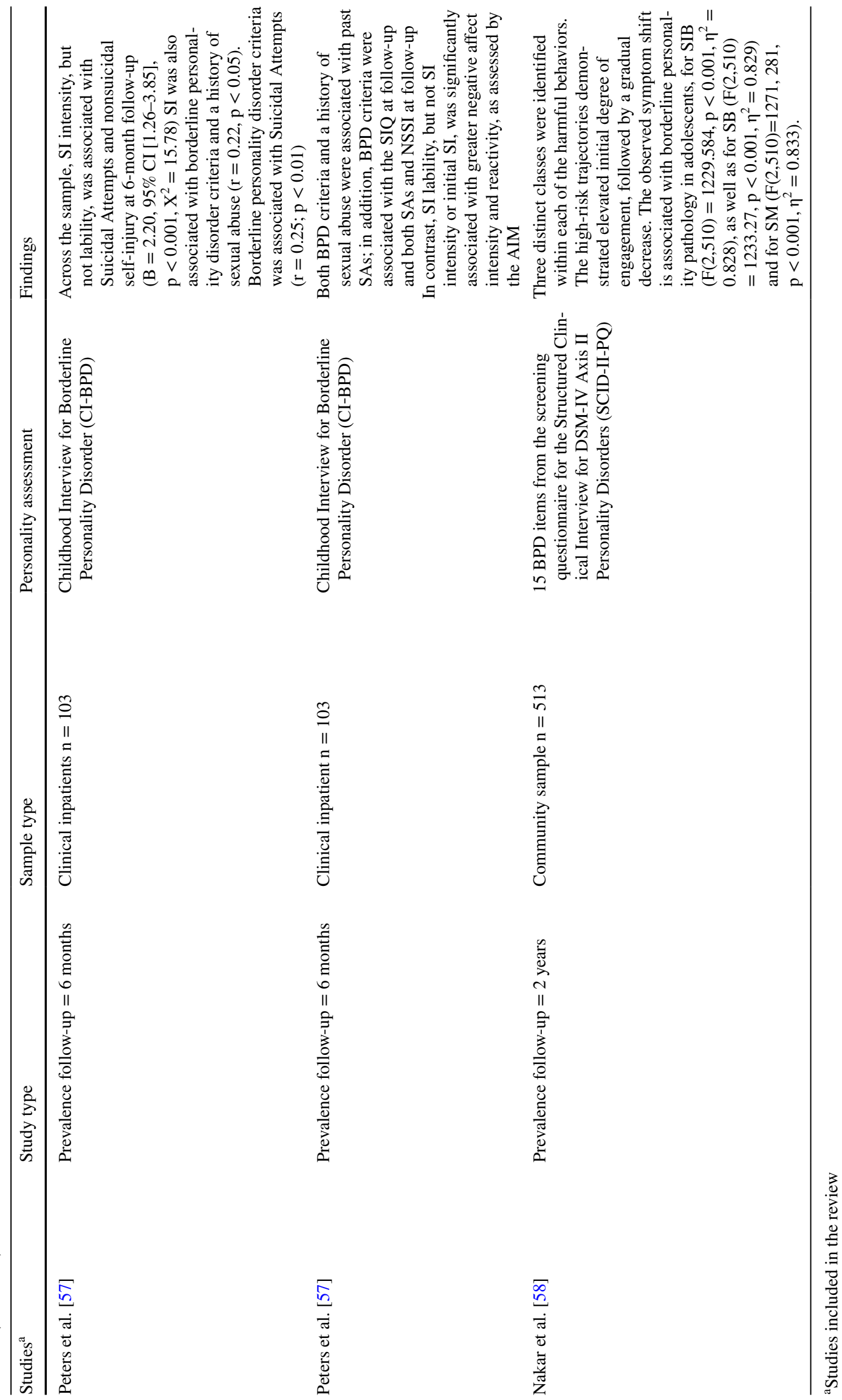


controlling for the effect of depressive symptoms and substance use problems in a sample of clinical inpatients, finding an independent incremental effect of identity disturbance and impulsivity on the variance seen in suicide risk scores [48]. In a clinical outpatient sample, Muehlenkamp et al. reported that the BPD symptoms of 'confusion about self' and 'unstable interpersonal relationships' allowed them to clearly distinguish between individuals with nonsuicidal self-injuries and those who self-harmed with concomitant suicidal ideation or suicide attempts [49]. Glenn and colleagues demonstrated that in a clinical sample, affective instability provided incremental utility in predicting suicidal behaviour above and beyond negative mood states [50]. Finally, Somma et al. profiled adolescents at risk of life-threatening suicide attempts using the Personality Inventory for DSM-5 (PID-5). The PID-5 traits of depressivity, anhedonia, and submissiveness, which significantly predict BPD diagnoses, were also significantly associated with adolescents' histories of life-threatening suicide attempts, even after controlling for a number of other variables, including mood disorder diagnoses [51]. Furthermore, depression and BPD seem to play a differential role in the development of suicidal risk: comparing BPD and MDD suicidal patients in terms of the characteristics of their suicidal behaviours, Horesh et al. found that aggression and impulsiveness were in fact positively correlated with suicidal behaviour only among BPD adolescents, whereas hopelessness and depression were positively correlated with suicidal behaviour in both diagnostic groups [43]. Research has also evidenced the relevance of suicidality to other personality dimensions related to diagnoses other than BPD. With the idea that adolescents who attempt suicide may constitute various groups, Cross et al. compared different types of suicide attempters and identified a narcissistic group [23]. Interestingly, this subtype was not characterized by anxiety or mood disorder diagnoses, had minimum substance abuse and conduct problems, was capable of high performance at school and had high adaptive functioning. In contrast, low narcissism scores, measured by the Narcissistic Personality Inventory, have been negatively associated with severe suicidal behaviour [52]. A personality trait that is often associated with a narcissistic personality pathology is perfectionism. Regarding suicidality, the selected studies showed that this personality construct-specifically, socially prescribed perfectionism (SPP)— can be considered an important moderating factor. Indeed, Donaldson and colleagues investigated the relationship between SPP, hopelessness and depressive cognitions in a clinical sample, finding that self-criticism was closely related to hopelessness, which in turn resulted in a greater risk of suicidal behaviour in adolescent attempters [53]. Finally, in a clinical sample, Freudenstein et al. found that adolescent inpatients with high levels of suicidal behaviour were more depressive and more prone to SPP than adolescent inpatients with lower levels of suicidal behaviour [52]. Moreover, some studies have indicated that personality traits that might be considered precursors of antisocial personality disorders (such as aggressiveness, anger, destructive behaviour, impulsivity and conduct disorders) are associated with suicidal behaviour. One study found that all these traits, when present 6 months before admission, were connected to suicidal behaviour. Furthermore, this study found that in male attempters, antisocial behaviours were more present than in female counterparts, although this difference was not significant among non-attempters [54]. The same association between impulsive traits, suicide attempts and self-injurious behaviours was found by Javdani et al. [55]. Interestingly, the authors noted that these traits contributed to self-harming behaviours above the capacity of depression: in this study, that is, depressive symptoms were able to explain only general suicidal ideation, not behaviours. A study by Chabrol and Saint-Martin highlighted that the affective component of psychopathic traits independently predicted suicide; therefore, it would be erroneous for clinicians to assume that psychopathic traits are protective factors against suicide in adolescence [56]. Furthermore, Chabrol et al. found that sadistic traits were connected with suicidality across genders: self-reported sadistic traits explained unique variance in self-reported suicidality in non-clinical adolescents, a result consistent with the psychodynamic hypothesis linking sadism to the self and suicidality [57].

\section{Longitudinal Studies}

Among the selected articles, eight studies reported followup data from 6 months up to over 10 years examining the associations between specific PDs and suicidality. Only six studies focused on short-term outcomes (6 months) following hospitalization due to suicidal risk (severe suicidal ideation or behaviour). Overall, these studies indicated that while suicidal ideation in adolescents with BPD is not stable and decreases rapidly [42], BPD is an independent predictor of suicidal behaviour recurrence at the 6-month follow-up [35, 41, 42]. In Peters et al. s' study, ideation intensity was the best predictor of suicidal behaviours at this stage and was significantly correlated with BPD traits. The same authors found that BPD criteria were significantly associated with having made a previous suicide attempt, with the presence of suicidal ideation at baseline and with making a subsequent suicide attempt after 6 months [57]. These data were also confirmed by longer longitudinal studies. In a study on the stability and psychopathological associations of BPD characteristics, Greenfield et al. reported that 4 years after recruitment, $94.1 \%$ of adolescents who remained suicidal had BPD [36]. Another prospective study with a German cohort of adolescents analysed different trajectories with respect to the evolution of risk behaviours (suicidal conduct, 
self-harm, drug abuse) for a period of 2 years. The authors identified an incremental relationship between the estimated risk of suicidal behaviour in the high-risk group and BPD criteria [58].

\section{Discussion}

This review of PDs as a risk factor for suicidal ideation and conduct yielded some noteworthy findings. We found evidence of a high prevalence of PDs in adolescent samples with both suicidal ideation and behaviour (Table 1).

The first objective of our review was to demonstrate associations between any PD and suicidal ideation and behaviours. Only one study [32] included in this review focused on the relationship between PD and suicidal ideation, showing how the diagnosis of any PD was significantly associated with the severity of suicidal ideation on a longitudinal basis. Regarding suicidal conduct, our data revealed a higher prevalence of PD diagnosis in the adolescent suicidal population than in community samples [28-31]. In the samples of adolescents with suicidal behaviours, the prevalence amounted to $19.5-22.8 \%$ among attempters and $29.6-42.1 \%$ among victims. In a recent review by Kongerslev et al., the prevalence of PDs in adolescent community samples and primary care settings generally ranged from 6 to $17 \%$ across studies [13]. Johnson and Cohen provided evidence of a differential distribution due to age, with this investigation's group of 14-year-olds having a prevalence of being diagnosed with any PD of $14.6 \%$, compared to $18.1 \%$ among the group of 16-year-olds [59]. This result shows how the prevalence of diagnoses of any PD in the general population is lower than that characterizing the adolescent suicidal clinical population. Based on the data contained in this review, it was not feasible to compare the distribution of personality diagnoses in the adolescent clinical samples, because in all the studies we encountered, it was not possible to ascertain the percentage of suicidal patients included in the samples. With reference to comparisons with adult suicidal populations, the data emerging from this review showed a rate of PDs in the adolescent suicidal population that was comparable and even higher than the distribution of diagnoses of PDs in studies of suicidal adults. In the first review of autopsy studies, Isometsa found a percentage of personality diagnoses that varied between 0 and 57\%, with no differentiation between community and clinical samples and no clear discussion as to the reasons for this variability [60]. A meta-analysis by Arsenault-Lapierre et al. confirmed that in adulthood, PDs, along with affective, substance-related and psychotic disorders, accounted for most of the diagnoses among suicidal patients, with a prevalence of PD diagnoses of $16 \%$ [9]. As further evidence of the association between PDs and adolescent suicide, the longitudinal study of Grohlt and Ekeberg using a 9-year follow-up after a suicide attempt during adolescence found that the most common disorders in adulthood were depression (46\%), PDs (46\%) and anxiety disorders (42\%) [28].

The second objective of our review was to demonstrate the association between specific personality disorders and/ or traits and suicidal ideation and behaviours. Of the studies included in this review, none reported an assessment of the whole range of DSM PD categories. Indeed, the only studies considering the multiplicity of PD diagnoses relied upon the ICD-10 categories [30, 31]. In these studies, diverse personality pathology areas were associated with suicidality, including psychotic, represented by paranoid personality disorder, impulsive-dysregulated, represented by dissocial and emotionally dysregulated personality disorder, and anxious, represented by dependent and anankastic personality disorder. In particular, impulsive-dysregulated personality pathology has been found to be over-represented among suicidal patients [30, 31]. The variants of PDs associated with suicidality certainly deserve more painstaking and systematic exploration. In most of the studies considered in this review, the researchers directly addressed the role of BPD [36-50], probably due the importance that this PD has assumed for adult suicidal patients. Nevertheless, despite its marked incidence in these studies, BPD also showed a wide range of prevalence, with frequencies varying between 56.3 and $90.9 \%$ when considering suicidality in terms of both ideation and behaviours [34-36] and between 48.6 and $62 \%$ when accounting only for suicide attempts in samples with more than 100 subjects $[39,44]$. Three other studies reported percentages lower than $27 \%$, most likely owing to their sample recruitment procedures and smaller sample sizes [37, 38, 45]. Only two studies investigated the rate of suicidal behaviours in BPD samples [41, 42], showing a high incidence of suicide attempts $(51.5 \%$ and $76 \%$, respectively). Although these studies included only hospitalized patients, it is interesting to compare them with the actual incidence of suicide attempts in the adolescent population: up to $10.6 \%$ for girls and $5.4 \%$ for boys and up to $3.6 \%$ for girls and $1.8 \%$ for boys for suicide attempts that required medical attention [61]. The relevance of BPD for suicidality in adolescence has also been stressed by cross-sectional studies showing that BPD mediates the impact of mood disorders on suicidal ideation and conduct $[46,47]$ and by studies indicating how specific BPD features can incrementally influence suicidality, adding to the effect of depression and substance abuse, two prominent risk factors for adult suicidality [35, 45, 48-51]. Finally, the relationship between BPD diagnosis and suicidality in adolescents also seemed to be confirmed at a longitudinal level, particularly for suicidal behaviours, but not ideation, where the presence of BPD or traits known to be predictors 
of suicide recurrence. Furthermore, it is important to stress that BPD represents a predictor of future suicide attempts in adolescence independent of other risk factors, thus confirming the utility of such a PD diagnosis for the clinical management of suicidality in this phase of development. One longitudinal study from adolescence through adulthood, not included in this review, evidenced that in a large community sample, BPD symptoms diagnosed in adolescence emerged as the only significant predictor of both proximal and lifetime suicide attempts after controlling for depression severity, early adversity, suicidal ideation and NSSI [62]. Indeed, BPD diagnosis in adolescence remains a stable predictor of future suicide attempts even if the suicide rate originally associated with this diagnosis tends to decrease over time [36]. It should also be noted that adolescent suicidality is a relevant predictor of BPD diagnosis in adulthood [63].

Regarding the third objective, the contributions examined mainly focused on dimensions related to borderline, narcissistic and antisocial traits. The literature has presented evidence that several dimensions related to BPD, namely, affective lability, impulsivity, aggression and identity problems, all seem to exert an important influence on suicidality in adolescence. However, it is unclear whether one of these traits is more effective in predicting suicide [35, 48-51]. This review has also evidenced the relevance of pathological dimensions of personality related to narcissistic personality disorder (NPD) [23, 52, 53], even though no specific reference was made to this DSM diagnosis in the contributions examined. The features or personality traits related to narcissistic pathology associated with suicidality in adolescence comprise a range of symptoms, not all of which are included in the prototypical DSM criteria, and some potentially describe alternative pathological narcissism profiles $[23,53]$. In the Collaborative Longitudinal Personality Disorders Study, a 10-year longitudinal research project, NPD was significantly associated with a larger number of suicide attempts, while BPD was significantly associated only with the presence of at least one suicide attempt [64]. Ansell et al. have demonstrated the predictive role of NPD for repetitive suicide attempts, pointing to the role of the peculiar quality of emotional deregulation following narcissistic wounds that lead to increased hostility and aggression [64]. Psychopathological and genetic studies have highlighted a mixed endophenotypical background for both BPD and NPD, characterized by emotional deregulation and hostility that may combine in the two PDs as strong predictors of suicidality $[11,64,65]$. Finally, studies in this review also investigated personality traits associated with antisocial personality organization, such as aggressiveness, anger, destructive behaviour, impulsivity and sadistic traits [55-57], confirming the presence of a suicidal risk in this type of population, as was also observed an adult forensic sample [13].

\section{Conclusions}

Among a vast array of risk factors, PDs are predictive and associated with suicidal ideation and behaviours both at cross-sectional and longitudinal levels in adolescence. From a clinical point of view, these considerations stress the need for personality evaluations in populations at risk of suicidal behaviours. In light of this review, further research clarifying the presence of specific PDs associated with suicidal risk and identifying possible common or single personality dimensions that enhance adolescents' risk of suicide is necessary. Such a research approach would facilitate more targeted preventive intervention in this area of risk. In general, it should be noted that most of the studies selected in this review reported only data on the rate of PDs in the adolescent suicidal population, whereas a more informative approach could be provided by studies describing the incidence of suicidal ideation and conduct in populations selected on the basis of PD diagnoses. More data should also be collected with follow-up monitoring of suicidal risk in adolescents previously diagnosed with PDs. Finally, many studies excluded from this review have generically pooled together self-harm, ideation and suicide attempts without clearly distinguishing the suicidal nature of self-harm behaviours. Although several studies have evidenced the role of self-harm and NSSI in suicidal risk, it is important to more clearly specify the link between these types of conduct and the various steps of the suicidal process by assessing individuals' suicidal intent.

\section{Summary}

This work presented a review of research papers examining the role of emerging personality pathology in suicidal ideation and suicidal behaviours in adolescence. The purpose of this contribution was to assess the prevalence and association with suicidal ideations and conduct of (1) overall PD diagnoses or traits, (2) specific PD diagnoses or traits, and (3) personality pathological dimensions.

We therefore searched for studies combining the presence of suicidal ideation or behaviour in clinical or community populations of subjects between 13 and 18 years of age with an emerging personality pathology. We excluded studies that did not distinguish NSSI from suicidality. Out of 2576 generated records, 230 studies were screened in accordance with PRISMA guidelines, with 33 articles considered for this review. The data reviewed revealed percentages ranging from 19.5 to $22.8 \%$ of any PD in suicide attempt samples and from 29.6 to $42.1 \%$ in autopsy studies of suicidal patients. The overwhelming majority of studies 
have focused on BPD, with longitudinal studies highlighting the predictive role of BPD for suicidal conduct. This study of pathological personality traits has substantiated that specific BPD features such as affective instability, impulsivity and identity diffusion can incrementally influence suicidality. Furthermore, other personality pathology dimensions, such as aggressiveness, sadism and perfectionism traits, also show a significant mediating role for suicidal risk.

PDs are associated with and help predict suicidal behaviour at both cross-sectional and longitudinal levels. From a clinical point of view, a personality assessment should be mandatory for evaluating suicidal risk, while from a research point of view, more studies integrating categorical and dimensional approaches to the assessment of personality pathology are needed.

Acknowledgements All authors meet the requirements for authorship.

Funding Open access funding provided by Università degli Studi di Roma La Sapienza within the CRUI-CARE Agreement. This research did not receive any specific grant from funding agencies in the public, commercial, or not-for-profit sectors.

Data Availability Data sharing is not applicable to this article as no new data were created or analyzed in this study.

\section{Declarations}

Conflict of interest The authors declare that they have no conflict of interest.

Open Access This article is licensed under a Creative Commons Attribution 4.0 International License, which permits use, sharing, adaptation, distribution and reproduction in any medium or format, as long as you give appropriate credit to the original author(s) and the source, provide a link to the Creative Commons licence, and indicate if changes were made. The images or other third party material in this article are included in the article's Creative Commons licence, unless indicated otherwise in a credit line to the material. If material is not included in the article's Creative Commons licence and your intended use is not permitted by statutory regulation or exceeds the permitted use, you will need to obtain permission directly from the copyright holder. To view a copy of this licence, visit http://creativecommons.org/licenses/by/4.0/.

\section{References}

1. World Health Organization (2014). Preventing suicide: a global imperative. Retrieved from https://www.who.int/mental_health/ suicide-prevention/world_report_2014/en/

2. Cha CB, Franz PJM, Guzmán E, GlennKleimanNock CREMMK (2018) Annual research review: suicide among youth — epidemiology, (potential) etiology, and treatment. J Child Psychol Psychiatry 59(4):460-482. https://doi.org/10.1111/jcpp.12831

3. Centers for Disease Control and Prevention (2020). Retrived from https://www.cdc.gov/violenceprevention/suicide/fastfact.html
4. Nock MK, Green JG, Hwang I, McLaughlin KA, Sampson NA, Zaslavsky AM, Kessler RC (2013) Prevalence, correlates, and treatment of lifetime suicidal behavior among adolescents: results from the National Comorbidity Survey Replication Adolescent Supplement. JAMA Psychiatry 70(3):300-310. https://doi.org/10. 1001/2013.jamapsychiatry.55

5. Holma KM, Haukka J, Suominen K, Valtonen HM, Mantere O, Melartin TK, Sokero TP, Oquendo MA, Isometsä ET (2014) Differences in incidence of suicide attempts between bipolar I and II disorders and major depressive disorder. Bipolar Disord 16:652-661. https://doi.org/10.1111/bdi.12195

6. De Crescenzo F, Serra G, Maisto F, Uchida M, Woodworth H, Casini MP, Baldessarini MD, Vicari S (2017) Suicide attempts in juvenile bipolar versus major depressive disorders: systematic review and meta-analysis. J Am Acad Child Adolesc Psychiatry 56(10):825-831. https://doi.org/10.1016/j.jaac.2017.07.783

7. Krysinska K, Heller TS, De Leo D (2006) Suicide and deliberate self-harm in personality disorders. Curr Opin Psychiatry 19(1):95-101. https://doi.org/10.1097/01.yco.0000191498.69281. $5 \mathrm{e}$

8. Giner L, Blasco-Fontecilla H, Perez-Rodriguez MM, Garcia-Nieto R, Giner J, Guija JA, Rico A, Barrero E, Luna MA, de Leon J, Oquendo MA, Baca Garcia E (2013) Personality disorders and health problems distinguish suicide attempters from completers in a direct comparison. J Affect Disord 151(2):474-483. https:// doi.org/10.1016/j.jad.2013.06.029

9. Arsenault-Lapierre G, Kim C, Turecki G (2004) Psychiatric diagnoses in 3275 suicides: a meta-analysis. BMC Psychiatry 4(1):37. https://doi.org/10.1186/1471-244X-4-37

10. Tyrer P, Reed GM, Crawford MJ (2015) Classification, assessment, prevalence, and effect of personality disorder. Lancet 385(9969):717-726. https://doi.org/10.1016/S0140-6736(14) 61995-4

11. McGirr A, Renaud J, Bureau A, Seguin M, Lesage A, Turecki G (2008) Impulsive-aggressive behaviours and completed suicide across the life cycle: a predisposition for younger age of suicide. Psychol Med 38(3):407. https://doi.org/10.1017/S003329170 7001419

12. Kim CD, Lesage A, Seguin M, Chawky N, Vanier C, Lipp O, Turecki G (2003) Patterns of co-morbidity in male suicide completers. Psychol Med 33(7):1299. https://doi.org/10.1017/S0033 291703008146

13. Kongerslev MT, Chanen AM, Simonsen E (2015) Personality disorder in childhood and adolescence comes of age: a review of the current evidence and prospects for future research. Scand J Child Adolesc Psychiatry Psychol 3(1):31-48. https://doi.org/10.21307/ sjcapp-2015-004

14. American Psychiatric Association (2013) Diagnostic and statistical manual of mental disorders, 5th edn. American Psychiatric Association, Arlington

15. Newton-Howes G, Clark LA, Chanen A (2015) Personality disorder across the life course. Lancet 385(9969):727-734. https://doi. org/10.1016/S0140-6736(14)61283-6

16. Winograd G, Cohen P, Chen H (2008) Adolescent borderline symptoms in the community: prognosis for functioning over 20 years. J Child Psychol Psychiatry 49(9):933-941. https://doi. org/10.1111/j.1469-7610.2008.01930.x

17. Caspi A, Houts RM, Belsky DW, Goldman-Mellor SJ, Harrington $\mathrm{H}$, Israel S et al (2014) The p factor: one general psychopathology factor in the structure of psychiatric disorders? Clin Psychol Sci 2(2):119-137. https://doi.org/10.1177/2167702613497473

18. Sanislow CA, Little TD, Ansell EB, Grilo CM, Daversa M, Markowitz JC et al (2009) Ten-year stability and latent structure of the DSM-IV schizotypal, borderline, avoidant, and obsessivecompulsive personality disorders. J Abnorm Psychol 118(3):507. https://doi.org/10.1037/a0016478 
19. Brown TA, Barlow DH (2005) Dimensional versus categorical classification of mental disorders in the fifth edition of the Diagnostic and statistical manual of mental disorders and beyond: comment on the special section. J Abnorm Psychol 114(4):551. https:// doi.org/10.1037/0021-843X.114.4.551

20. Kendler KS, Gardner CO, Lichtenstein P (2008) A developmental twin study of symptoms of anxiety and depression: evidence for genetic innovation and attenuation. Psychol Med 38(11):15671575. https://doi.org/10.1017/S003329170800384X

21. Strickland CM, Hopwood CJ, Bornovalova MA, Rojas EC, Krueger RF, Patrick CJ (2019) Categorical and dimensional conceptions of personality pathology in DSM-5: toward a model-based synthesis. J Pers Disord 33(2):185-213. https://doi.org/10.1521/ pedi_2018_32_339

22. Sevecke K, Schmeck K, Krischer M (2014) The dimensional-categorical hybrid model of personality disorders in DSM-5 from an adolescent psychiatric perspective-criticism and critical outlook. Zeitschrift fur Kinder-und Jugendpsychiatrie und Psychotherapie 42(4):279-283. https://doi.org/10.1024/1422-4917/a000300

23. Cross D, Westen D, Bradley B (2011) Personality subtypes of adolescents who attempt suicide. J Nerv Ment Dis 199(10):750-756. https://doi.org/10.1097/NMD.0b013e31822fcd38

24. Turner BJ, Dixon-Gordon KL, Austin SB, Rodriguez MA, Rosenthal MZ, Chapman AL (2015) Non-suicidal self-injury with and without borderline personality disorder: differences in selfinjury and diagnostic comorbidity. Psychiatry Res 230(1):28-35. https://doi.org/10.1016/j.psychres.2015.07.058

25. Rossouw TI, Fonagy P (2012) Mentalization-based treatment for self-harm in adolescents: a randomized controlled trial. J Am Acad Child Adolesc Psychiatry 51(12):1304-1313. https://doi. org/10.1016/j.jaac.2012.09.018

26. Chanen AM, Jovev M, Djaja D, McDougall E, Yuen HP, Rawlings D, Jackson HJ (2008) Screening for borderline personality disorder in outpatient youth. J Pers Disord 22(4):353-364. https:// doi.org/10.1521/pedi.2008.22.4.353

27. Groholt B, Ekeberg Ø (2009) Prognosis after adolescent suicide attempt: mental health, psychiatric treatment, and suicide attempts in a nine-year follow-up study. Suicide Life-Threat Behav 39(2):125-136. https://doi.org/10.1521/suli.2009.39.2.125

28. Villar F, Castellano-Tejedor C, Verge M, Sánchez B, BlascoBlasco T (2018) Predictors of suicide behavior relapse in pediatric population. Span J Psychol. https://doi.org/10.1017/sjp.2018.7

29. Houston K, Hawton K, Shepperd R (2001) Suicide in young people aged 15-24: a psychological autopsy study. J Affect Disord 63(1-3):159-170. https://doi.org/10.1016/S0165-0327(00) 00175-0

30. Portzky G, Audenaert K, van Heeringen K (2005) Suicide among adolescents. Soc Psychiatry Psychiatr Epidemiol 40(11):922-930. https://doi.org/10.1007/s00127-005-0977-x

31. Tairi T, Milojev P, Zilikis N (2018) Clinical profiles among Greek adolescent suicide attempters: a latent class analysis. Crisis 39(5):335. https://doi.org/10.1027/0227-5910/a000506

32. Ayodeji E, Green J, Roberts C, Trainor G, Rothwell J, Woodham A, Wood A (2015) The influence of personality disorder on outcome in adolescent self-harm. Br J Psychiatry 207(4):313-319. https://doi.org/10.1192/bjp.bp.113.138941

33. Kuba T, Yakushi T, Fukuhara H, Nakamoto Y, Singeo ST Jr, Tanaka O, Kondo T (2011) Suicide-related events among child and adolescent patients during short-term antidepressant therapy. Psychiatry Clin Neurosci 65(3):239-245. https://doi.org/10.1111/j. 1440-1819.2011.02204.x

34. Greenfield B, Henry M, Weiss M, Tse SM, Guile JM, Dougherty G, Zhan X, Fombonne E, Lis E, Lapalme-Remis S, Harnden B (2008) Previously suicidal adolescents: predictors of six-month outcome. J Can Acad Child Adolesc Psychiatry 17(4):197. https:// doi.org/10.1007/s00787-014-0589-9

35. Greenfield B, Henry M, Lis E, Slatkoff J, Guilé JM, Dougherty $\mathrm{G}$ et al (2015) Correlates, stability and predictors of borderline personality disorder among previously suicidal youth. Eur Child Adolesc Psychiatry 24(4):397-406. https://doi.org/10.1007/ s00787-014-0589-9

36. Fritsch S, Donaldson D, Spirito A, Plummer B (2000) Personality characteristics of adolescent suicide attempters. Child Psychiatry Hum Dev 30(4):219-235. https://doi.org/10.1023/B:CHUD.00000 37151.02381 .52

37. Kato K, Mikami K, Nishino R, Akama F, Yamada K, Maehara $M$ et al (2012) Frequency and clinical features of borderline personality disorder in adolescent suicide attempts in Japan. Asian J Psychiatry 5(4):363. https://doi.org/10.1016/j.ajp.2012.01.012

38. Yen S, Weinstock LM, Andover MS, Sheets ES, Selby EA, Spirito A (2013) Prospective predictors of adolescent suicidality: 6-month post-hospitalization follow-up. Psychol Med 43(5):983. https://doi.org/10.1017/S0033291712001912

39. Selby EA, Yen S (2014) Six-month trajectory of suicidal ideation in adolescents with borderline personality disorder. Suicide LifeThreat Behav 44(1):89-100. https://doi.org/10.1111/sltb.12057

40. Horesh N, Orbach I, Gothelf D, Efrati M, Apter A (2003) Comparison of the suicidal behavior of adolescent inpatients with borderline personality disorder and major depression. J Nerv Ment Dis 191(9):582-588. https://doi.org/10.1097/01.nmd.0000087184. 56009.61

41. Goodman M, Tomas IA, Temes CM, Fitzmaurice GM, Aguirre BA, Zanarini MC (2017) Suicide attempts and self-injurious behaviours in adolescent and adult patients with borderline personality disorder. Pers Ment Health 11(3):157-163. https://doi. org/10.1002/pmh.1375

42. Knafo A, Guilé JM, Breton JJ, Labelle R, Belloncle V, Bodeau N et al (2015) Coping strategies associated with suicidal behaviour in adolescent inpatients with borderline personality disorder. Can J Psychiatry. Revue canadienne de psychiatrie 60(2 Suppl 1):S46

43. Kawashima Y, Ito T, Narishige R, Saito T, Okubo Y (2012) The characteristics of serious suicide attempters in Japanese adolescents-comparison study between adolescents and adults. BMC Psychiatry 12(1):191. https://doi.org/10.1186/1471-244X-12-191

44. Yen S, Gagnon K, Spirito A (2013) Borderline personality disorder in suicidal adolescents. Pers Ment Health 7(2):89-101. https:// doi.org/10.1002/pmh.1216

45. Rodgers RF, van Leeuwen N, Chabrol H, Leichsenring F (2011) An exploration of the role of defensive psychopathology in adolescent suicidal ideation and behavior. Bull Menn Clin 75(3):236253. https://doi.org/10.1521/bumc.2011.75.3.236

46. Sharp C, Green KL, Yaroslavsky I, Venta A, Zanarini MC, Pettit $\mathbf{J}$ (2012) The incremental validity of borderline personality disorder relative to major depressive disorder for suicidal ideation and deliberate self-harm in adolescents. J Pers Disord 26(6):927-938. https://doi.org/10.1521/pedi.2012.26.6.927

47. Yalch MM, Hopwood CJ, Fehon DC, Grilo CM (2014) The influence of borderline personality features on inpatient adolescent suicide risk. Pers Disord Theory Res Treat 5(1):26-31. https:// doi.org/10.1037/per0000027

48. Muehlenkamp JJ, Ertelt TW, Miller AL, Claes L (2011) Differentiating non-suicidal self-injury in adolescent outpatients: symptoms of borderline personality disorder. J Child Psychol Psychiatry 52(2):148-155. https://doi.org/10.1111/j.1469-7610. 2010.02305.x

49. Glenn CR, Bagge CL, Osman A (2013) Unique associations between borderline personality disorder features and suicide ideation and attempts in adolescents. J Pers Disord 27(5):604-616. https://doi.org/10.1521/pedi_2013_27_102 
50. Somma A, Fossati A, Terrinoni A, Williams R, Ardizzone I, Fantini $F$ et al (2016) Reliability and clinical usefulness of the personality inventory for DSM-5 in clinically referred adolescents: a preliminary report in a sample of Italian inpatients. Compr Psychiatry 70:141-151. https://doi.org/10.1016/j.comppsych.2016. 07.006

51. Freudenstein O, Valevski A, Apter A, Zohar A, Shoval G, Nahshoni E et al (2012) Perfectionism, narcissism, and depression in suicidal and nonsuicidal adolescent inpatients. Compr Psychiatry 53(6):746-752. https://doi.org/10.1016/j.comppsych.2011.08.011

52. Donaldson D, Spirito A, Farnett E (2000) The role of perfectionism and depressive cognitions in understanding the hopelessness experienced by adolescent suicide attempters. Child Psychiatry Hum Dev 31(2):99-111. https://doi.org/10.1023/a:1001978625 339

53. Fennig S, Geva K, Zalzman G, Weitzman A, Fennig S, Apter A (2005) Effect of gender on suicide attempters versus nonattempters in an adolescent inpatient unit. Compr Psychiatry 46(2):90-97. https://doi.org/10.1016/j.comppsych.2004.07.037

54. Javdani S, Sadeh N, Verona E (2011) Suicidality as a function of impulsivity, callous-unemotional traits, and depressive symptoms in youth. J Abnorm Psychol 120(2):400. https://doi.org/10.1037/ a0021805

55. Chabrol H, Saint-Martin C (2009) Psychopathic traits and suicidal ideation in high-school students. Arch Suicide Res 13(1):64-73. https://doi.org/10.1080/13811110802572155

56. Chabrol H, van Leeuwen N, Rodgers RF (2011) Exploratory study of the relations between sadistic traits and suicidality in a nonclinical sample of adolescents. Bull Menn Clin 75(3):224-235. https://doi.org/10.1521/bumc.2011.75.3.224

57. Peters JR, Mereish EH, Solomon JB, Spirito AS, Yen S (2019) Suicide ideation in adolescents following inpatient hospitalization: examination of intensity and lability over 6 months. Suicide Life-Threat Behav 49(2):572-585. https://doi.org/10.1111/sltb. 12448

58. Nakar O, Brunner R, Schilling O, Chanen A, Fischer G, Parzer P et al (2016) Developmental trajectories of self-injurious behavior, suicidal behavior and substance misuse and their association with adolescent borderline personality pathology. J Affect Disord 197:231-238. https://doi.org/10.1016/j.jad.2016.03.029

59. Johnson JG, Cohen P, Kasen S, Skodol AE, Oldham JM (2008) Cumulative prevalence of personality disorders between adolescence and adulthood. Acta Psychiatr Scand 118(5):410-413. https://doi.org/10.1111/j.1600-0447.2008.01231.x

60. Isometsä ET (2001) Psychological autopsy studies-a review. Eur Psychiatry 16(7):379-385. https://doi.org/10.1016/S09249338(01)00594-6

61. Shain B (2016) Suicide and suicide attempts in adolescents. Pediatrics. https://doi.org/10.1542/peds.2016-1420

62. Scott LN, Pilkonis PA, Hipwell AE, Keenan K, Stepp SD (2015) Non-suicidal self-injury and suicidal ideation as predictors of suicide attempts in adolescent girls: a multi-wave prospective study. Compr Psychiatry 58:1-10. https://doi.org/10.1016/j.comppsych. 2014.12.011

63. Brière FN, Rohde P, Seeley JR, Klein D, Lewinsohn PM (2015) Adolescent suicide attempts and adult adjustment. Depress Anxiety 32(4):270-276. https://doi.org/10.1002/da.22296

64. Ansell EB, Wright AG, Markowitz JC, Sanislow CA, Hopwood CJ, Zanarini MC et al (2015) Personality disorder risk factors for suicide attempts over 10 years of follow-up. Pers Disord Theory Res Treat 6(2):161. https://doi.org/10.1037/per0000089

65. Bornovalova MA, Hicks BM, Iacono WG, McGue M (2009) Stability, change, and heritability of borderline personality disorder traits from adolescence to adulthood: a longitudinal twin study. Dev Psychopathol 21(4):1335. https://doi.org/10.1017/S0954 579409990186

66. Moher D, Liberati A, Tetzlaff J, Altman DG, The PRISMA Group (2009) Preferred Reporting Items for Systematic Reviews and Meta-Analyses: the PRISMA statement. PLoS Med 6(7):e1000097. https://doi.org/10.1371/journal.pmed.1000097

Publisher's Note Springer Nature remains neutral with regard to jurisdictional claims in published maps and institutional affiliations. 